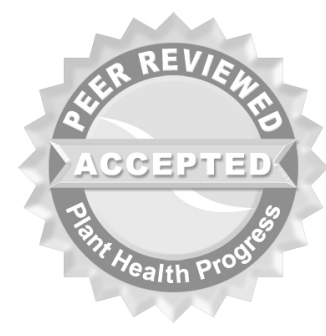

(c) 2008 Plant Management Network.

Accepted for publication $18 \mathrm{~J}$ une 2008. Published 18 August 2008.

\title{
First Report of Wisteria vein mosaic virus in Wisteria sinensis in the United States of America
}

Rayapati A. Naidu and Gandhi Karthikeyan, Department of Plant Pathology, Irrigated Agriculture Research and Extension Center, Washington State University, Prosser 99350

Corresponding author: Rayapati A. Naidu. naidu@wsu.edu

Naidu, R. A., and Karthikeyan, G. 2008. First report of Wisteria vein mosaic virus in Wisteria sinensis in the United States of America. Online. Plant Health Progress doi: 10.1094/PHP-2008-0818-01-BR.

The ornamental Chinese wisteria (Wisteria sinensis) is a woody perennial grown for its flowering habit in home gardens and landscape settings. We have observed wisteria plants in several retail nurseries in Washington State showing foliar symptoms consisting of mild mosaic mottling, chlorotic spots, necrotic flecks, and distortion or twisting of leaflets (Fig. 1). These symptoms were observed only in young leaves, whereas mature leaves showed no apparent symptoms. Inoculation of Nicotiana benthamiana plants with crude sap extracts prepared from symptomatic leaves of wisteria showed mild mosaic symptoms. Symptomatic leaves from wisteria and N. benthamiana tested positive in antigen coated plate ELISA with potyvirus group-specific antibodies (Agdia Inc., Elkhart, IN) indicating the presence of potyvirus in these samples. Total RNA was extracted from symptomatic leaves of wisteria and N. benthamiana using a RNeasy plant minikit (Qiagen Inc., Valencia, CA) and used in reverse transcription-polymerase chain reaction (RT-PCR). The RT-PCR assay was carried out (RT at $52^{\circ} \mathrm{C}$ for $60 \mathrm{~min}$ followed by $5 \mathrm{~min}$ initial incubation at $94^{\circ} \mathrm{C}$ and 35 cycles of PCR with each cycle consisting of $30 \mathrm{sec}$ denaturation at $94^{\circ} \mathrm{C}, 45 \mathrm{sec}$ annealing at $55^{\circ} \mathrm{C}$, and 60 sec extension at $72^{\circ} \mathrm{C}$ followed by $7 \mathrm{~min}$ final extension step at $72^{\circ} \mathrm{C}$ ) using potyvirus degenerate primers, PNIbF1: 5'-GGBAAYAATAGTGGNCAACC-3' and PCPR1: 5'GGGGAGGTGCCGTTCTCDATRCACCA-3' (4). A single DNA fragment of approximately 1000 nucleotides covering the $3^{\prime}$ end of the NIb gene and the $5^{\prime}$ end of the CP gene was amplified from total RNA of symptomatic but not healthy leaves (Fig. 2). The DNA band was weaker from wisteria when compared to the corresponding band from $\mathrm{N}$. benthamiana probably due to a lower virus concentration or the presence of inhibitors in the wisteria. The DNA fragment amplified from both plants was cloned separately into pCR2.1 Topo vector (Invitrogen Corp., Carlsbad, CA). Two independent clones per plant were sequenced from both orientations. Pair wise comparison of these sequences showed $100 \%$ sequence identity. A comparison of the consensus sequence (GenBank accession number: EU677749) with corresponding sequences of potyviruses in the GenBank showed maximum identity of $86 \%$ and $94 \%$ at the nucleotide and amino acid level in the $\mathrm{NIb} / \mathrm{CP}$ region of Wisteria vein mosaic virus (WVMV) reported from China (GenBank accession number AY656816). These results further confirm the presence of WVMV in symptomatic leaves of W. sinensis and indicate that the virus is distinct from the Chinese isolate. Although a mosaic disease was first recorded in 1957 in W. floribunda in the USA (1), the causal agent was reported as WVMV in 1984 based on serology (2). WVMV was reported in W. sinensis from China and other countries (3) and molecular analysis of $\mathrm{NIb} / \mathrm{CP}$ region reported in this study represents the first confirmed report of the virus in Chinese wisteria in the USA. 


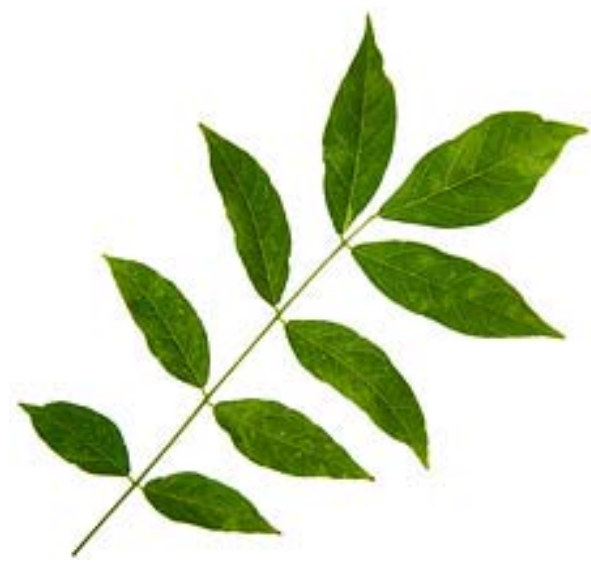

Fig. 1A. W. sinensis leaf showing chlorotic spots, blotches, and leaf distortion.
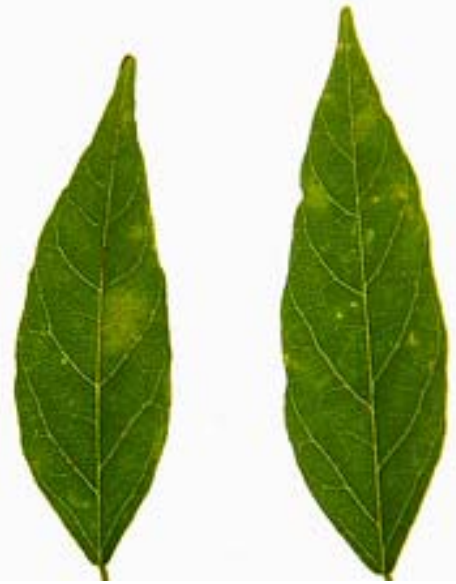

Fig. 1B. Leaflets showing chlorotic spots, blotches, and necrotic flecks along the minor and major veins.

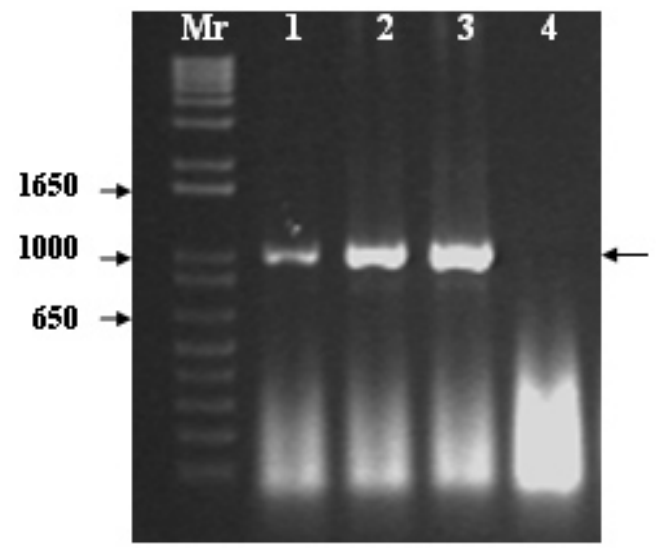

Fig. 2. RT-PCR analysis of total RNA extracted from WVMV-infected leaves of W. sinensis (lane 1) and $\mathrm{N}$. benthamiana (lanes 2 and 3 ). A single DNA fragment of approximately 1 kilobase pairs (shown by arrow on the right side) was amplified only from total RNA extracted from infected leaves and not healthy leaves (lane 4). Size of DNA molecular weight markers (lane Mr) are shown on the left side.

W. sinensis is native to China. Therefore, it is not known if the plants originally imported into the USA were infected with WVMV or if they were infected from other Wisteria species during propagation in the greenhouse settings. Nevertheless, the results presented here suggest that distribution of WVMV-infected W. sinensis plants for horticultural purposes through wholesale and retailers could pose the risk of spreading the virus to different parts of the country. In addition, due to the perennial nature of wisteria, growing virusinfected plants in a virgin area could potentially serve as a continuous source for resident aphid vectors to spread the virus to other susceptible plant species in the vicinity, thereby facilitating the expansion of the host-range of WVMV. Lack of clearly visible symptoms and "masking" of symptoms in mature leaves makes it difficult to determine health status of plants based on visual diagnosis. Therefore, it is important for wholesale nurseries to test for WVMV to ensure sanitary status of source plants during propagation to prevent wide spread occurrence of WVMV. 
Literature Cited

1. Brierley, P., and Lorentz, P. 1957. Wisteria mosaic and peony leaf curl, two diseases of ornamental plants caused by viruses transmissible by grafting but not by sap inoculation. Plant Dis. Reptr. 41:691-693.

2. Halliwell, R. S., and Porterfield, M. R. 1984. First report of a potyvirus infecting Wisteria floribunda in the United States. Plant Dis. 68:450.

3. Liang, W. X., Song, L. M., Tian, G. Z., Li, H. F., and Fan, Z. F. 2006. The genomic sequence of Wisteria vein mosaic virus and its similarities with other potyviruses. Arch. Virol. 151:2311-2319.

4. Hsu, Y. C., Yeh, T. J., and Chang, Y. C. 2005. A new combination of RT-PCR and reverse dot blot hybridization for rapid detection and identification of potyviruses. J. Virol. Meth. 128:54-60. 